Supplement of The Cryosphere, 8, 1589-1605, 2014

http://www.the-cryosphere.net/8/1589/2014/

doi:10.5194/tc-8-1589-2014-supplement

(c) Author(s) 2014. CC Attribution 3.0 License.

(c) (i)

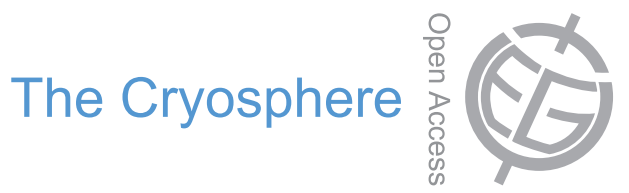

Supplement of

\title{
Sensitivity of lake ice regimes to climate change in the Nordic region
}

S. Gebre et al.

Correspondence to: S. Gebre (solomon.gebre@ntnu.no, solomongbr@yahoo.com) 


\section{SUPPLEMENTARY MATERIAL}

\section{Lake ice model description}

The lake model used is MyLake (Multi-year simulation model for Lake thermo- and phytoplankton dynamics) which is a one dimensional process-based model. It simulates at a daily time step the vertical distribution of lake-water temperature, evolution of seasonal lake-ice and snow cover thickness and phosphorus-phytoplankton dynamics (Saloranta and Andersen, 2007; Saloranta et al., 2009). The most important physical, chemical, and biological processes are included in a relatively simple and transparent model structure which is coded in Matlab. MyLake was designed to be an investigative tool with a short runtime, allowing the simulation of a large number of lakes and over long periods.

The model includes computational methods for simulating heat transfer at the air-water interface, advective heat transfer of inflow and outflow, and the internal vertical diffusion of thermal energy. The vertical profile of the lake is conceptualized as horizontal layers of equal height $(\Delta Z)$, each of them having a defined area and hence volume. The one-dimensional heat conservation equation for the temperature distribution in a horizontally homogeneous, vertically stratified lake is solved in each layer. The equation can be written as (Saloranta and Andersen, 2007):

$$
A \frac{\partial T}{\partial t}=\frac{\partial}{\partial z}\left[K A \frac{\partial T}{\partial z}\right]+A \frac{H^{*}}{\rho_{w} C_{p}}
$$

where $\mathrm{T}$ is laterally averaged water temperature $\left[{ }^{\circ} \mathrm{C}\right], \mathrm{K}$ is the vertical diffusion coefficient $\left[\mathrm{m}^{2} \mathrm{~d}^{-1}\right]$, $\mathrm{H}^{*}$ is the net local heating rate (net heat flux) $\left[\mathrm{J} \mathrm{m}^{-2} \mathrm{~d}^{-1}\right]$, A is surface area of a particular element $\left[\mathrm{m}^{2}\right], \mathrm{z}$ is the depth from the water surface $[\mathrm{m}], \mathrm{t}$ is time [days], $C_{p}$ is the specific heat capacity of water $\left[\mathrm{J} \mathrm{kg}^{-1}{ }^{\circ} \mathrm{C}^{-1}\right]$ and $\rho_{w}$ is the density of water $\left[\mathrm{kg} \mathrm{m}^{-3}\right]$. While $\mathrm{T}, \mathrm{K}$, and $\mathrm{H}^{*}$ are functions of depth $(\mathrm{z})$ and time $(\mathrm{t}), \mathrm{A}$ is a function of depth alone.

The vertical diffusion coefficient $\mathrm{K}$, which quantifies the turbulent mixing between adjacent layers, is calculated on the basis of the stability frequency (Hondzo and Stefan, 1993) :

$$
N^{2}=\frac{g}{\rho_{w}}\left(\frac{\partial \rho_{w}}{\partial z}\right) ; K=a_{k}\left(N^{2}\right)^{-0.43}
$$

Where $a_{k}=0.00706\left(A_{s}\right)^{0.56}, A_{s}$ being the lake surface area in $\mathrm{km}^{2}$. 
For the top layer of the lake the net surface energy flux is calculated as:

$$
H^{*}=H_{S W}+H_{L W}+H_{S e n}+H_{L a t}+H_{P r}+H_{\text {Sed }}
$$

Where $H_{S W}$ is the incoming solar radiation absorbed by the layer, $H_{L W}$ is the net long-wave radiation, $H_{\text {Sen }}$ and $H_{\text {Lat }}$ are the sensible and latent heat fluxes, $\mathrm{H}_{P r}$ is heat advected due to precipitation, and $H_{\text {Sed }}$ is the heat flux at sediment-water interface (all in $\mathrm{J} \mathrm{m}^{-2} \mathrm{~d}^{-1}$ ). For the subsurface layers, only $H_{S W}$ and $H_{\text {Sed }}$ contribute to the local heating rate $H^{*}$. During the ice cover period only the sediment water flux and the shortwave radiations penetrating through snow and ice contribute to the local heating.

In order to compute all these fluxes the following daily meteorological variables should be provided as input series: air temperature at $2 \mathrm{~m}$ height $\left({ }^{\circ} \mathrm{C}\right)$, cloud cover $(0-1)$, relative humidity $(\%)$, global solar radiation $\left(\mathrm{J} \mathrm{m}^{-2} \mathrm{~d}^{-1}\right)$, wind speed at $10 \mathrm{~m}$ height $\left(\mathrm{m} \mathrm{s}^{-1}\right)$, air pressure at station level $(\mathrm{hPa})$ and precipitation ( $\left.\mathrm{mm} \mathrm{d}^{-1}\right)$. If solar insolation observations are not available (as is the case in our study), MyLake computes the global solar radiation $\left(\mathrm{H}_{\mathrm{G}}\right)$ using Reed's bulk formula (Reed, 1977) as:

$H_{G}=H_{o} \phi(\alpha) f(C)$

$\phi(\alpha)=0.377+0.00513 \alpha$

$$
\begin{aligned}
& f(C)=1.0-0.62 C+0.0019 \alpha \quad \text { for } C \geq 0.3, \\
& f(C)=1 \quad \text { for } C<0.3
\end{aligned}
$$

Where $\mathrm{C}$ is the total cloudiness in tenth, $\alpha$ is noon (maximum) solar altitude in degree, and $\mathrm{H}_{\mathrm{o}}$ is the downward extra-terrestrial (i.e., no-sky) solar radiation computed as a function of day of the year and geographical position using the MATLAB Air-Sea Toolbox (Beardsley et al., 1998).

The transmission and absorption of solar radiation in the snow, ice and within the water body are described by the Lambert-Beer law as $H_{S W}(z, t)=\mathrm{H}_{\mathrm{G}}(\mathrm{t})(1-\beta) \exp (-\lambda \mathrm{z})$, where $H_{S W}(z, t)$ is the net irradiance at depth $\mathrm{z}, \mathrm{H}_{\mathrm{G}}$ is the global incoming radiation, both in Jules, $\beta$ is the albedo, and $\lambda$ is the attenuation/extinction coefficient $\left(\mathrm{m}^{-1}\right)$. The albedo of water surface is computed from the atmospheric transmittance and sun altitude according to Payne (1972) using the Air-Sea Toolbox. Snow and ice albedos are input as parameters. During the ice covered period, solar radiation penetrating the snowice layer is attenuated according to $H_{S W}(z, t)=\mathrm{H}_{\mathrm{G}}(\mathrm{t})(1-\beta) \exp \left(-\lambda_{\mathrm{i}} \mathrm{h}_{\mathrm{i}}\right) * \exp \left(\lambda_{\mathrm{s}} \mathrm{h}_{\mathrm{s}}\right)$, where $\lambda_{\mathrm{i}}, \lambda_{\mathrm{s}}$ are attenuation coefficients of ice and snow, $h_{i}, h_{s}$ are ice and snow thicknesses, and $\beta$ is the albedo of snow if $h_{s}>0$ or albedo of ice if snow is not present. 
Wind has a strong influence on the lake thermal stratification in open water period. Due to the wind stress the surface water is forced to move. Depending of the wind strength, this movement is transmitted to the underlying water layers until a certain depth. In MyLake the total kinetic energy TKE (J) accumulated over one time step of 24 hours $(\Delta \mathrm{t}=86400 \mathrm{~s})$, available for wind-induced mixing in open water period is calculated by:

$$
\mathrm{TKE}=\mathrm{W}_{\mathrm{str}} \mathrm{A}_{\mathrm{s}} \sqrt{\frac{\tau^{3}}{\rho}} \Delta \mathrm{t}
$$

Where $\tau$ is wind stress $\left(\mathrm{N} . \mathrm{m}^{-2}\right)$ calculated from the input wind speed using the MATLAB Air-Sea Toolbox. $\mathrm{W}_{\text {str }}$ is a wind sheltering coefficient which is calculated using the empirical relationship developed by Hondzo and Stefan (1993):

$$
\mathrm{W}_{\mathrm{str}}=1.0-\exp \left(-0.3 \mathrm{~A}_{\mathrm{s}}\right)
$$

The model triggers ice formation when water layer temperature drops below the freezing point and the temperature of the super-cooled layers is set to the water freezing point. The sensible heat deficit in the super-cooled layer is turned into a latent heat of freezing and an initial ice-layer is created. However, this ice is defined as frazil ice. Before the formation of an ice-cover, ice-crystals are suspended in the water column and grow until they float to the surface and form a slushy layer which freezes to form the initial ice- cover. The thickness of frazil ice increases whenever new super-cooled water is encountered, and decreases whenever the water column receives heat to melt the frazil ice. The initial solid ice-cover, associated to the freeze-up date predicted by the model, only appears when the accumulation of frazil ice reaches a threshold thickness of $3 \mathrm{~cm}$. Once a solid ice cover has been formed, additional ice thickness due to congelation ice growth is calculated whenever the air temperature $\mathrm{T}_{\mathrm{a}}\left({ }^{\circ} \mathrm{C}\right)$ is below the freezing point using Stefan's law (Leppäranta, 1993).

$$
h_{\text {ice_new }}=\sqrt{h_{\text {ice }}^{2}+\frac{2 \kappa_{\text {ice }}}{\rho_{\text {ice }} L}\left(T_{f}-T_{\text {ice }}\right) \Delta \mathrm{t}}
$$

where $\kappa_{\text {ice }}\left(\mathrm{W} .{ }^{\circ} \mathrm{C}^{-1} \cdot \mathrm{m}^{-1}\right)$ is the thermal conductivity of ice, $\rho_{\text {ice }}\left(\mathrm{kg} \cdot \mathrm{m}^{-3}\right)$ the density of ice, $\mathrm{L}\left(\mathrm{J} \cdot \mathrm{kg}^{-1}\right)$ the latent heat of freezing, $\Delta \mathrm{t}(\mathrm{s})$ the daily time step.

Using the input precipitation series, the snow fall amount is calculated in water equivalent at a daily time step. The actual thickness of the snow layer is computed as $h_{s}=h_{s_{-} w e q}\left(\rho_{w} / \rho_{s}\right)$ where $\rho_{s}$ is the bulk density of the snow cover $\left(\mathrm{kg} \mathrm{m}^{-3}\right)$. When the weight of snow cover exceeds the buoyancy 
capacity of the ice layer, the ice surface submerges and water floods on the top of ice. This water mixes with the lower layer of the snow cover and forms slush and becomes 'snow-ice' when it freezes. Snow-ice formation is modeled using Equation 8, which essentially makes the assumption that there is isostatic balance and that free water pathways always exist. The water-soaked snow layer is assumed to be compacted directly to the density of ice, and hence turned into a snow-ice layer. The thickness of a new snow-ice is computed as:

$$
\Delta h_{s i}=\max \left[0, h_{i c e}\left(\left(\frac{\rho_{\text {ice }}}{\rho_{w}}\right)-1\right)+h_{S_{-} w e q}\right]
$$

Where $\mathrm{h}_{\mathrm{s}_{-} \text {weq }}$ is the thickness of the snow layer in water equivalents. White-ice properties are assumed to be the same as congelation ice, and thus the newly formed white-ice layer is subtracted from the snow cover and added to the ice layer.

MyLake also considers the snow insulation effect. This is done while computing the temperature of the ice surface, $\mathrm{T}_{\mathrm{ice}}$.

$$
\mathrm{T}_{\text {ice }}=\left(\mathrm{p} * \mathrm{~T}_{\mathrm{f}}+\mathrm{T}_{\mathrm{a}}\right) /(1+\mathrm{p})
$$

where $T_{f}$ is water freezing point, $T_{a}$ is air temperature. And, the factor $p$ is parameterized as, $p=\max$ $\left(\mathrm{k}_{\text {ice }} * \mathrm{~h}_{\mathrm{s}} / \mathrm{k}_{\mathrm{s}} \mathrm{h}_{\text {ice }}, 1 /\left(10 \mathrm{~h}_{\text {ice }}\right)\right)$, where $\mathrm{k}_{\text {ice }}$ and $\mathrm{k}_{\mathrm{s}}$ are thermal conductivities for ice and snow. Thus, when there is snow cover $T_{\text {ice }}$ becomes warmer than $T_{a}$ due to the insulating effect.

Lake ice decay or melt is computed by considering the net heat flux at the air-snow or air-ice interface. The net heat flux is used to melt the snow cover first before ice melt starts. The formulation for melt (snow and ice) is given as:

$$
\text { melt }_{i, S}=\max \left[0, \frac{\left(1-A_{c o e f f}\right) * H_{S W}+H_{L W}+H_{S L}}{\rho_{i, S} * L_{i, S}}\right]
$$

Where $\mathrm{i}$ and $\mathrm{s}$ refer to snow and ice, $\mathrm{A}_{\text {coeff }}$ is the ice/snow attenuation coefficient, $\mathrm{H}_{\mathrm{SW}}$ is the net short wave radiation, $\mathrm{H}_{\mathrm{LW}}$ is the net long wave radiation, $\mathrm{H}_{\mathrm{SL}}$ is the net sensible and latent heat flux, $\rho_{\mathrm{i}, \mathrm{s}}$ is the density of ice/snow and $\mathrm{L}_{\mathrm{i}, \mathrm{s}}$ is the latent heat of ice/snow. For computing the net shortwave radiation, $\mathrm{H}_{\mathrm{Sw}}$, snow and ice albedo are assigned default values of 0.77 and 0.30 , respectively. 
The heat exchange between water and ice, $\mathrm{H}_{\mathrm{Wi}}\left(\mathrm{Jm}^{-2}\right)$ is computed as, $\mathrm{H}_{\mathrm{wi}}=\left(\mathrm{T}_{\mathrm{z}, 1}-\mathrm{T}_{\mathrm{f}}\right) \mathrm{C}_{\mathrm{w}} \mathrm{dz}$ where $T_{z, 1}$ is water temperature of the first layer, $T_{f}$ is temperature of the under-layer of ice, $C_{w}$ is the volumetric heat capacity of water $\left(4.18 \mathrm{e}+6 \mathrm{~J} \mathrm{~K}^{-1} \mathrm{~m}^{-3}\right)$, and $\mathrm{dz}(=1 \mathrm{~m})$ is the layer depth $(\mathrm{m})$.

The model also takes into account lake inflows and outflows. The inflow either flows over the reservoir surface if the inflow density is less, or plunges beneath the surface if the inflow density is greater, i.e., river inflow is added to the top of the first water layer heavier than the inflow. The water column above the inflow level is then lifted up according to the volume of the inflowing water. Outflow from a lake occurs at the surface when the water level exceeds the lake surface elevation. Hence, the part of the water column that is lifted above the lake surface level (assumed to be constant) is considered as the outflow and thus lost from the lake.

\section{References:}

Beardsley, R.C., Dever, E.P., Lentz, S.J. and Dean, J.P., 1998. Surface heat flux variability over the northern California shelf. Journal of Geophysical Research: Oceans, 103(C10): 21553-21586.

Hondzo, M. and Stefan, H., 1993. Lake Water Temperature Simulation Model. Journal of Hydraulic Engineering, 119(11): 1251-1273.

Leppäranta, M., 1993. A review of analytical models of sea-ice growth. Atmosphere-Ocean, 31(1): 123-138.

Payne, R.E., 1972. Albedo of the Sea Surface. Journal of the Atmospheric Sciences, 29: 959-970.

Reed, R.K., 1977. On Estimating Insolation over the Ocean. Journal of Physical Oceanography, 7(3): $482-485$

Saloranta, T.M. and Andersen, T., 2007. MyLake-A multi-year lake simulation model code suitable for uncertainty and sensitivity analysis simulations. Ecological Modelling, 207: 45-60.

Saloranta, T.M., Forsius, M., Järvinen, M. and Arvola, L., 2009. Impacts of projected climate change on the thermodynamics of a shallow and a deep lake in Finland: model simulations and Bayesian uncertainty analysis. Hydrology Research, 40(2-3): 234-248. 